\title{
MULTISCALE NUMERICAL MODELING OF DEFORMATION RESPONSES OF HETEROGENEOUS MATERIALS
}

\author{
Jurica Sorić, Zdenko Tonković, Tomislav Lesičar
}

\begin{abstract}
Summary
A multiscale computational algorithm employing the second-order computational homogenization under assumption of large strain is presented. A macro-micro transition procedure has been derived, where the discretization at the macrolevel has been performed by the newly developed $C^{1}$ continuity displacement based finite elements. The representative volume element at the microlevel is discretized by using standard $C^{0}$ continuity finite elements. The performed verifications of the proposed $C^{1}$ finite element formulation show an advantage in comparison to available finite elements based on mixed formulations. In order to improve numerical efficiency of the computational procedures, the new algorithms are embedded into the finite element program Abaqus. The performance of the presented multiscale homogenization approach is demonstrated in numerical examples, where the elastoplastic deformation responses are displayed.
\end{abstract}

Keywords: Large strains; second-order homogenization; multiscale computational approach; $C^{1}$ continuity finite element; heterogeneous materials.

\section{INTRODUCTION}

To achieve reliability and safety of structures, an advanced structural analysis employing more realistic description of material behavior is required. Therein, material heterogeneity and anisotropy play a major role, because almost all materials are heterogeneous and anisotropic due to their natural structure, particularly on the microscopic scale, or as the result of manufacturing procedure. Besides rock, concrete, wood, fiber reinforced composites and other similar materials, heterogeneous metals such as nodular cast iron are widely used as the material of structural components in mechanical engineering such as, for example, in the structures of wind turbine. Herein the nodular cast iron is material of hub and hollow shaft, Fig. 1. 


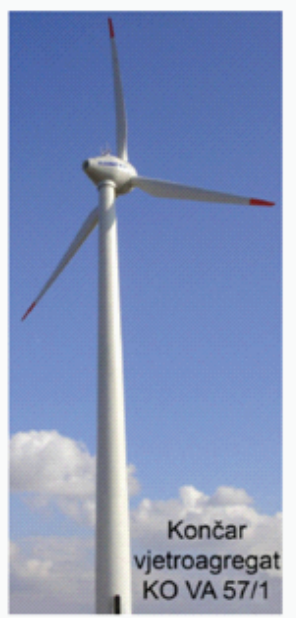

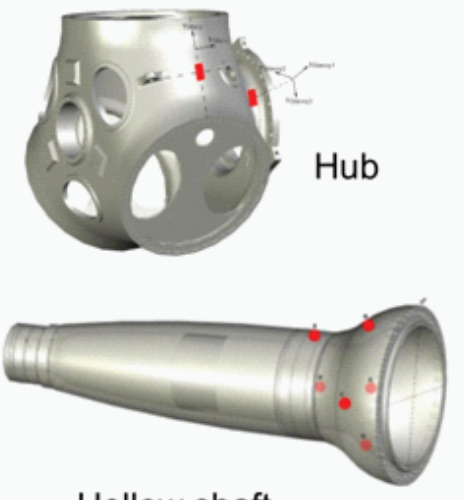

Hollow shaft

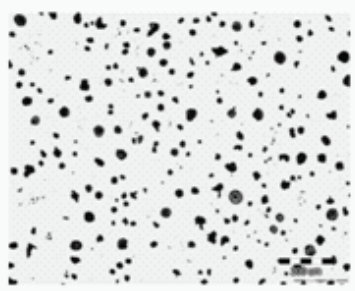

Metallography of nodular cast iron

Fig. 1. Wind turbine structural components

SI. 1. Konstrukcijske komponente vjetroturbine

The ductile nodular cast iron consists of graphite spheroids or nodules, positioned in a ferritic matrix providing large fatigue strength. The size, shape, spatial distribution, volume fraction and the properties of the constituents making up the microstructure have a significant impact on the behavior of material properties observed at the macroscale [1]. Therefore, in order to assess structural integrity and reliability as well as to predict structural lifetime with higher accuracy, an analysis on the microlevel is unavoidable.

During recent years, a special attention has been directed to the investigation of the relations between the macroscopic material behavior and its microstructure, and various numerical multiscale techniques have been developed. For micro-macro numerical procedures mostly applied for heterogeneous materials, several homogenization methods are available such as the mathematical method of homogenization, the MoriTanaka method, the double inclusion model, the numerical homogenization, etc., as can be found in $[2,3]$. However, in more recent formulations the two-scale computational homogenization approach has mostly been used [4-10]. This computational approach is based on the solution of two boundary value problems, one at the macroscopic and one at the microscopic scale. The results obtained by the simulation of a statistically representative sample of material, named the Representative Volume Element (RVE), at the microscopic scale are used as input data for the modeling at the macrolevel. To avoid the complex and time consuming computational procedure, instead of the realistic 3D representative volume element, an academic 2D sample is usually considered. A macromicro transition scheme is presented in Fig. 2. 


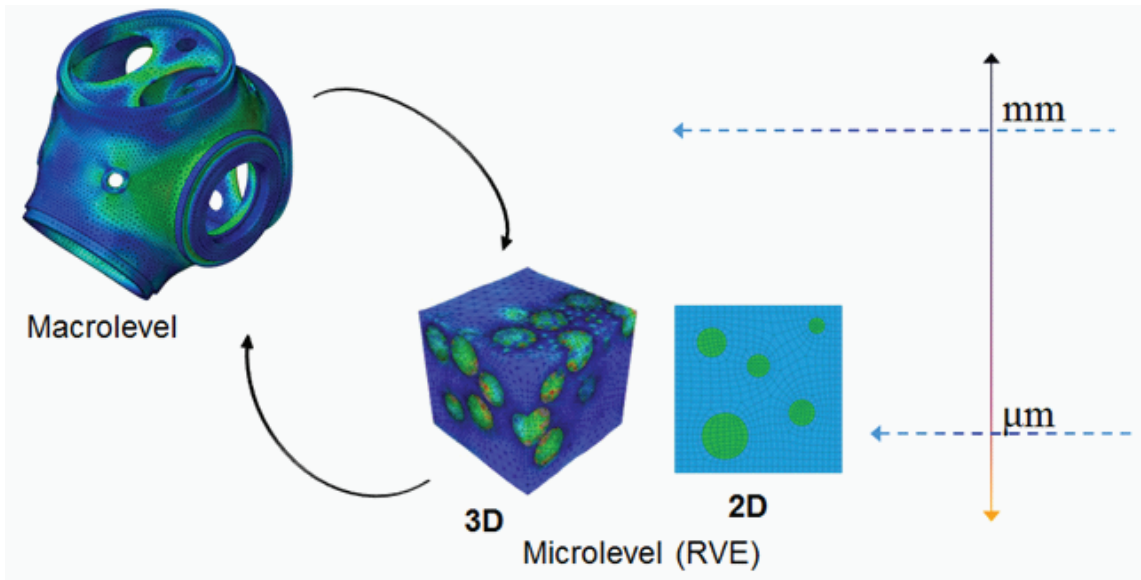

Fig. 2. Macro-micro transition scheme

SI. 2. Makro-mikro prijenosna shema

The computation does not require an explicit constitutive relation at the macrolevel, which allows the modeling of complex microstructure geometry as well as deformation responses. The results obtained by the homogenization such as the tangent stiffness and the stress tensors depend on the imposed RVE boundary conditions. The periodic boundary conditions are mostly used and have advantage in comparison to the boundary conditions such as the prescribed displacements and tractions.

Based on the micro-macro variable dependence, the first-order and the second-order homogenization procedures are available. The first-order homogenization scheme is based on the principle of a classical continuum theory, whereby the stress at a material point depends only on the strain (and other state variables) at the same point. It holds in the case when the wavelength of a deformation field at the macroscale is much larger than the dominant micro-structural length scale of the material. However, it is not adequate for the problems where the macroscopic stress-strain behavior depends on the characteristic size of the microstructure, and higher order effects such as strain localization phenomena and material softening are present. The second-order homogenization is based on a nonlocal strain gradient continuum theory that takes into account the influence of an environment on the behavior of a material point [11,12]. Herein the secondorder stress and strain are included. The multiscale analysis using the second-order homogenization approach may describe more complex deformation modes of the RVE. In addition, for the general case of a nonlinear material with softening or fracturing, the information about the higher-order strain have to be transmitted to the microstructure to get meaningful results. On the other hand, the second-order homogenization requires 
$C^{1}$ continuity at the numerical solution of the boundary value problem at macrolevel, which implicates the requirement that both displacements and strains must be continuous functions. The RVE discretization at microlevel is usually performed by assuming standard $C^{0}$ continuity to keep the micro boundary value problem as simple as possible. $C^{0}$ continuity means that only displacements are continuous functions.

For the numerical solution of the boundary value problem of a second-order continuum, finite element formulations are mostly used. To satisfy $C^{1}$ continuity mentioned above, shape functions and at least their first derivatives are required in the conventional displacement-based finite element framework. The displacement based $C^{1}$ finite element formulations for gradient elasticity may be found in [13-15]. The disadvantage of this formulation is a complex shape function and a large number of degrees of freedom. Another strain gradient finite element concept is based on the mixed finite element formulation, where the continuity requirements are fulfilled only in a weak sense [16-21] using $C^{0}$ continuous functions. In other words, only shape functions should be continuous. Certain authors have developed other numerical methods for the implementation of gradient elasticity such us meshless methods [22-24] and boundary element methods $[25,26]$. In spite of a large effort which has been directed towards the derivation of different numerical formulations, even now there is a strong motivation to devise a suitable discretization of strain gradient boundary value problem.

The mixed finite element strain gradient formulations have been employed in [27$29]$ for the solution of the boundary value problem in the multiscale analysis. Herein the second-order computational homogenization under assumption of large strain responses has been derived. The analogous small strain formulation is presented in [5]. The strain gradient $C^{1}$ continuity triangular finite element has been employed in the second-order two-scale homogenization procedure under assumption of small strain by the authors of this contribution in [30]. The same authors have also proposed a large strain multiscale approach in [31]. Herein, to improve numerical efficiency, the micro-macro computational strategy has been embedded into the finite element computer program Abaqus [32].

This paper deals with a two-scale computational algorithm employing the secondorder computational homogenization under assumption of large strain. The discretization at the macrolevel is performed by using the $C^{1}$ continuity plane strain triangular finite element, in which the second-order large strain theory is employed. The microlevel discretization is performed over the RVE by means of the $C^{0}$ continuity finite element formulation. The homogenization procedure in the micro-macro transition is derived by using the generalized periodic boundary conditions.

The paper is organized as follows. Section 2 is concerned with the basic relations of the second-order large strain theory and a homogenization procedure at microscopic 
scale. In Section 3, the $C^{1}$ continuous large strain finite element formulation is derived. The implementation of the finite element and the two-scale computational algorithm into finite element program Abaqus are described. The finite element verification is also included. In Section 4, the performance of the second-order micro-macro homogenization approach is tested by the numerical examples where the elastoplastic analyses are performed. The concluding remarks are given in Section 5.

\section{TWO-SCALE LARGE STRAIN FORMULATION}

\subsection{Basic relations}

Here the basic relations of the second-order large strain theory used at the macrolevel are presented briefly. The deformation gradient, and its gradient are defined as $\mathbf{F}=\nabla_{0} \mathbf{x}$ and $\mathbf{G}=\nabla_{0} \mathbf{F}=\nabla_{0}\left(\nabla_{0} \mathbf{x}\right)$, respectively, where the gradient operator $\nabla_{0}$ is taken with respect to the reference (undeformed or initial) configuration. Herein a material point at the reference configuration defined by the position vector $\mathbf{X}$ is mapped into the current or deformed configuration at the point with the position vector $\mathbf{X}$, where the displacement field is defined as $\mathbf{u}=\mathbf{x}-\mathbf{X}$. The values $\mathbf{F}$ and $\mathbf{G}$ are the second- and the third-order tensors, respectively [27,29]. The internal energy conjugates to $\mathbf{F}$ and $\mathbf{G}$ are the first Piola-Kirchhoff stress tensor $\mathbf{P}$ and the double stress tensor $\mathbf{Q}$. The virtual work at an initially undeformed configuration of volume $V_{0}$ is expressed as

$$
\delta W_{0}^{\mathrm{int}}=\int_{V_{0}}(\mathbf{P}: \delta \mathbf{F}+\mathbf{Q}: \delta \mathbf{G}) \mathrm{d} V_{0} .
$$

Herein $\mathbf{P}: \delta \mathbf{F}$ and $\mathbf{Q} \vdots \delta \mathbf{G}$ express the double and the triple scalar products, respectively. Analogous to the procedure described in [30,31,33], using the divergence theorem and some integral transformations, the variation of the work done by the internal forces defined in Eq. (1) may be written as

$$
\begin{aligned}
\delta W_{0}^{\mathrm{int}} & =-\int_{V_{0}}\left[\nabla_{0} \cdot\left(\mathbf{P}-\left(\nabla_{0} \cdot \mathbf{Q}\right)\right)\right] \cdot \delta \mathbf{u} \mathrm{d} V_{0} \\
& +\int_{A_{0}}\left[\mathbf{n} \cdot\left(\mathbf{P}-\left(\nabla_{0} \cdot \mathbf{Q}\right)\right)+\left(\nabla_{0}^{A} \cdot \mathbf{n}\right) \mathbf{n} \cdot(\mathbf{n} \cdot \mathbf{Q})-\nabla_{0}^{A} \cdot(\mathbf{n} \cdot \mathbf{Q})\right] \cdot \delta \mathbf{u ~ d} A_{0} \\
& +\int_{A_{0}}[\mathbf{n} \cdot \mathbf{Q} \cdot \mathbf{n}] \cdot D_{0} \delta \mathbf{u d} A_{0} .
\end{aligned}
$$


In this equation the displacement gradient $\nabla_{0} \delta \mathbf{u}$ is split into the surface gradient $\nabla_{0}^{A} \delta \mathbf{u}$ and the normal gradient $\mathbf{n} D_{0} \delta \mathbf{u}$ using the surface gradient operator $\nabla_{0}^{A}=(\mathbf{I}-\mathbf{n n}) \cdot \nabla_{0}$, and the normal gradient operator $D_{0}=\mathbf{n} \cdot \nabla_{0}$. The undeformed surface is denoted by $A_{0}$, while $\mathbf{n}$ is the unit outward normal to the surface. The external virtual work is expressed in the following form

$$
\delta W_{0}^{\mathrm{ext}}=\int_{A_{0}} \mathbf{t} \cdot \delta \mathbf{u} \mathrm{d} A_{0}+\int_{A_{0}} \boldsymbol{\tau} \cdot D_{0} \delta \mathbf{u} \mathrm{d} A_{0},
$$

where $\mathbf{t}$ and $\tau$ are the vectors of the surface and the double surface traction (load), respectively. The dot in the above relations denotes scalar product. Herein the body force is neglected.

\subsection{Homogenization at microscopic scale}

According to the two-scale computational homogenization strategy, in addition to the macroscopic second-order formulation based on the strain gradient theory, the boundary value problem at the microscopic scale is considered on a representative volume element. In this framework, the microscopic problem formulation obeys the classical continuum theory. Contrary to the requirement of $C^{1}$ continuity at the macrolevel, the $C^{0}$ finite element formulation is mostly used at the microlevel. The scale transition methodology in the second-order computational homogenization is already revealed in numerous publications such as $[5,31,33,34]$. Here, a brief review is presented.

For the solution of the RVE boundary value problem, the boundary conditions are expressed by the displacements which are related to the macroscopic kinematic values $\mathbf{F}_{\mathrm{M}}$ and $\mathbf{G}_{\mathrm{M}}$ according to the relation

$$
\mathbf{u}_{\mathrm{m}}=\mathbf{X}^{T}\left(\mathbf{F}_{\mathrm{M}}-\mathbf{I}\right)+\frac{1}{2}\left(\mathbf{X}^{T} \mathbf{G}_{\mathrm{M}} \mathbf{X}\right)+\mathbf{r}
$$

Here the macrovariables are denoted by the subscript "M", while the microvariables have subscript " $m$ ", as usually. $\mathbf{X}$ is a spatial coordinate on the RVE boundary, and $\mathbf{r}$ represents the microfluctuation field [30]. The RVE geometry is depicted in a standard way in Fig. 3. 


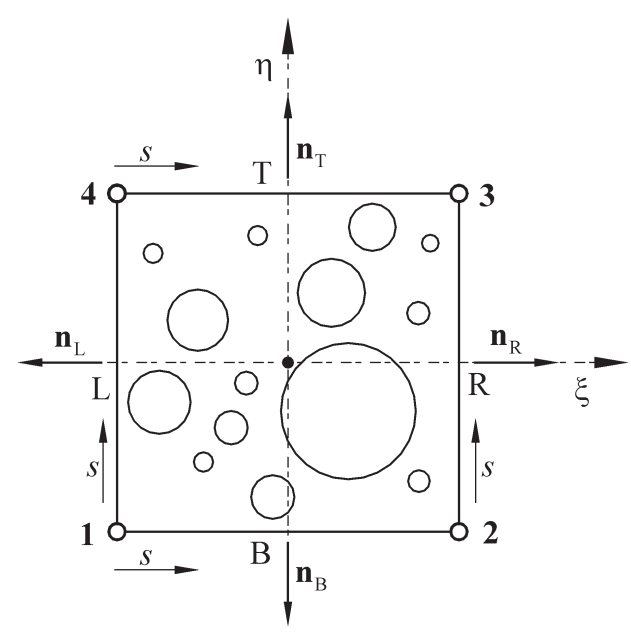

Fig. 3. Representative volume element

SI. 3. Reprezentativni volumni element

The condition that the macrogradients must be equal to the volume average of the microgradients, as shown in [5], yields

$$
\frac{1}{V_{0}} \int_{A_{0}}\left(\mathbf{n} \mathbf{r}^{T}\right) \mathrm{d} A_{0}=\mathbf{0} .
$$

Using the averaging theorem introduced in [27], by means of some mathematical manipulation and relation (4), the following new constraint on the microfluctuation field along the undeformed RVE boundary may be expressed as

$$
\int_{A_{0}}\left(\mathbf{n}^{T} \mathbf{r} \mathbf{X}+\mathbf{X}^{T} \mathbf{r} \mathbf{n}\right) \mathrm{d} A_{0}=\mathbf{0}
$$

For the generalized periodic boundary conditions, Eq. (5) is automatically satisfied, while Eq. (6) can be rewritten according to [33] in terms of the nodal displacements on the RVE boundaries as

$$
\begin{aligned}
& \int_{A_{\mathrm{L}}} \mathbf{u}_{\mathrm{L}} \mathrm{d} A=\left(\int_{A_{\mathrm{L}}} \mathbf{X}_{\mathrm{L}} \mathrm{d} A\right)^{T}\left(\mathbf{F}_{\mathrm{M}}-\mathbf{I}\right)+\left(\frac{1}{2} \int_{A_{\mathrm{L}}}\left(\mathbf{X}_{\mathrm{L}} \mathbf{X}_{\mathrm{L}}\right) \mathrm{d} A\right)^{T} \mathbf{G}_{\mathrm{M}}, \\
& \int_{A_{\mathrm{B}}} \mathbf{u}_{\mathrm{B}} \mathrm{d} A=\left(\int_{A_{\mathrm{B}}} \mathbf{X}_{\mathrm{B}} \mathrm{d} A\right)^{T}\left(\mathbf{F}_{\mathrm{M}}-\mathbf{I}\right)+\left(\frac{1}{2} \int_{A_{\mathrm{B}}}\left(\mathbf{X}_{\mathrm{B}} \mathbf{X}_{\mathrm{B}}\right) \mathrm{d} A\right)^{T} \mathbf{G}_{\mathrm{M}},
\end{aligned}
$$


where the subscripts " $\mathrm{L}$ " and "B" stand for the left and bottom boundaries. Using the Hill-Mandel energy condition in the form

$$
\frac{1}{V_{0}} \int_{V_{0}}\left(\delta \mathbf{F}_{\mathrm{m}}^{T} \mathbf{P}_{\mathrm{m}}\right) \mathrm{d} V_{0}=\delta \mathbf{F}_{\mathrm{M}}^{T} \mathbf{P}_{\mathrm{M}}+\delta \mathbf{G}_{\mathrm{M}}^{T} \mathbf{Q}_{\mathrm{M}},
$$

the first Piola-Kirchhoff stress tensor and the double stress tensor at the macrolevel may be written as the volume average

$$
\begin{aligned}
& \mathbf{P}_{\mathrm{M}}=\frac{1}{V_{0}} \int_{V_{0}} \mathbf{P}_{\mathrm{m}} \mathrm{d} V_{0}, \\
& \mathbf{Q}_{\mathrm{M}}=\frac{1}{2 V_{0}} \int_{V_{0}}\left(\mathbf{P}_{\mathrm{m}}^{T} \mathbf{X}+\mathbf{X}^{T} \mathbf{P}_{\mathrm{m}}\right) \mathrm{d} V_{0} .
\end{aligned}
$$

To derive the macrolevel tangent stiffness matrices, the static condensation procedure developed in [4,33,1/35], and presented in [30] for small strain assumption, is used. Accordingly, the linearized incremental constitutive relations for the second-order continuum at the macrolevel may be written in the following form

$$
\begin{aligned}
& \Delta \mathbf{P}_{\mathrm{M}}={ }^{4} \mathbf{C}_{\mathrm{PF}} \Delta \mathbf{F}_{\mathrm{M}}+{ }^{5} \mathbf{C}_{\mathrm{PG}} \Delta \mathbf{G}_{\mathrm{M}}, \\
& \Delta \mathbf{Q}_{\mathrm{M}}={ }^{5} \mathbf{C}_{\mathrm{QF}} \Delta \mathbf{F}_{\mathrm{M}}+{ }^{6} \mathbf{C}_{\mathrm{QG}} \Delta \mathbf{G}_{\mathrm{M}},
\end{aligned}
$$

where the constitutive tangent operators are given by

$$
\begin{aligned}
& { }^{4} \mathbf{C}_{\mathrm{PF}}=\frac{1}{V_{0}} \mathbf{D} \tilde{\mathbf{K}}_{\mathrm{bb}} \mathbf{D}^{T}, \\
& { }^{5} \mathbf{C}_{\mathrm{PG}}=\frac{1}{V_{0}} \mathbf{D} \tilde{\mathbf{K}}_{\mathrm{bb}} \mathbf{H}^{T}, \\
& { }^{5} \mathbf{C}_{\mathrm{QF}}=\frac{1}{V_{0}} \mathbf{H} \tilde{\mathbf{K}}_{\mathrm{bb}} \mathbf{D}^{T}, \\
& { }^{6} \mathbf{C}_{\mathrm{QG}}=\frac{1}{V_{0}} \mathbf{H} \tilde{\mathbf{K}}_{\mathrm{bb}} \mathbf{H}^{T},
\end{aligned}
$$


Here the left superscripts 4, 5, and 6 denote the order of the constitutive tensors. $\tilde{\mathbf{K}}_{\mathrm{bb}}$ is the RVE global stiffness matrix condensed to the boundary nodes, while D and $\mathbf{H}$ represent the coordinate matrices associated with the RVE boundary nodes [29].

\section{$3 C^{1}$ LARGE STRAIN FINITE ELEMENT FORMULATION}

\subsection{Finite element equation}

As evident from the above relations, the numerical solution of the boundary value problems using a discretization procedure requires at least $C^{1}$ continuous interpolation functions, which implies the continuity of displacement field and its derivatives. Here, a $C^{1}$ displacement based finite element formulation is proposed. Only displacement field as independent variable is considered as an advantage in comparison with other formulations employing the interpolation of both displacements and displacement gradients [27-29].

The $C^{1}$ plane strain triangular finite element based on the strain gradient theory and the small strain assumption has been described and used for the two-scale procedure in [30] by the authors of this paper. Here the small strain element formulation is extended to the finite strain theory.

As usually in finite element formulations, we start with the weak form of the boundary value problem of the undeformed continuum of volume $V_{0}$ bounded by surface $A_{0}$. According to relations (1) and (3), the principle of virtual work is used, which is expressed in matrix form as

$$
\int_{V_{0}}\left(\delta \mathbf{F}^{T} \mathbf{P}+\delta \mathbf{G}^{T} \mathbf{Q}\right) \mathrm{d} V_{0}=\int_{A_{0}} \delta \mathbf{u}^{T} \mathbf{t} \mathrm{d} A_{0}+\int_{A_{0}}\left(D_{0}(\delta \mathbf{u})\right)^{T} \boldsymbol{\tau} \mathrm{d} A_{0} .
$$

The internal values $\mathbf{F}$ and $\mathbf{G}$ may be written in terms of displacements as

$$
\begin{aligned}
& \mathbf{F}=\mathbf{I}+\nabla_{0} \mathbf{u}, \delta \mathbf{F}=\nabla_{0}(\delta \mathbf{u}), \\
& \mathbf{G}=\nabla_{0} \mathbf{F}, \delta \mathbf{G}=\nabla_{0} \delta \mathbf{F}=\nabla_{0}\left(\nabla_{0} \delta \mathbf{u}\right) .
\end{aligned}
$$

Exploiting Eq. (13), the principle of virtual work (12) can be rewritten in the following form

$$
\int_{V_{0}}\left(\left(\nabla_{0}(\delta \mathbf{u})\right)^{T} \mathbf{P}+\left(\nabla_{0}\left(\nabla_{0} \delta \mathbf{u}\right)\right)^{T} \mathbf{Q}\right) \mathrm{d} V_{0}=\int_{A_{0}} \delta \mathbf{u}^{T} \mathbf{t} \mathrm{d} A_{0}+\int_{A_{0}}\left(\nabla_{0}(\delta \mathbf{u})\right)^{T} \mathbf{T} \mathrm{d} A_{0} .
$$


where the double traction tensor expressed as $\mathbf{T}=\tau \mathbf{n}$ is introduced. To linearize boundary value problem, an incremental form of Eq. (14) should be derived. Accordingly, the state variables are updated in the defined time interval $\left(t^{i-1}, t\right)$ in which $t^{i-1}$ represents the last known equilibrium state. The new equilibrium is computed using an iterative procedure, where the state variables at time $t$ are given by

$$
\begin{aligned}
& \mathbf{u}=\mathbf{u}^{i-1}+\Delta \mathbf{u}, \\
& \delta \mathbf{u}=\delta(\Delta \mathbf{u}) \\
& \mathbf{P}=\mathbf{P}^{i-1}+\Delta \mathbf{P}, \\
& \mathbf{Q}=\mathbf{Q}^{i-1}+\Delta \mathbf{Q}
\end{aligned}
$$

Inserting the updates (15) into Eq. (14), we obtain

$$
\begin{aligned}
& \int_{V_{0}}\left[\left(\delta\left(\nabla_{0} \Delta \mathbf{u}\right)\right)^{T}\left(\mathbf{P}^{i-1}+\Delta \mathbf{P}\right)+\left[\delta\left(\nabla_{0}\left(\nabla_{0} \Delta \mathbf{u}\right)\right)\right]^{T}\left(\mathbf{Q}^{i-1}+\Delta \mathbf{Q}\right)\right] \mathrm{d} V_{0}= \\
& \int_{A_{0}} \delta(\Delta \mathbf{u})^{T} \mathbf{t} \mathrm{d} A_{0}+\int_{A_{0}}\left(\delta\left(\nabla_{0} \Delta \mathbf{u}\right)\right)^{T} \mathbf{T} \mathrm{d} A_{0} .
\end{aligned}
$$

Next, to discretize boundary value problem expressed by (16), the displacement field is approximated over the finite element domain by the interpolation functions $\mathbf{N}$ yielding the fundamental finite element relation

$$
\mathbf{u}=\mathbf{N} \mathbf{v},
$$

with $\mathbf{V}$ as the vector of nodal degrees of freedom. Accordingly, the gradients of the incremental displacements are expressed as

$$
\begin{aligned}
& \Delta \mathbf{u}=\mathbf{N} \Delta \mathbf{v}, \\
& \nabla_{0} \Delta \mathbf{u}=\Delta \mathbf{F}=\mathbf{B}_{\mathrm{F}} \Delta \mathbf{v}, \\
& \nabla_{0}\left(\nabla_{0} \Delta \mathbf{u}\right)=\Delta \mathbf{G}=\mathbf{B}_{\mathrm{G}} \Delta \mathbf{v} .
\end{aligned}
$$

In Eq. (18), $\mathbf{B}_{\mathrm{F}}$ and $\mathbf{B}_{\mathrm{G}}$ are the matrices containing the first and second partial derivatives of the interpolation functions $\mathbf{N}$, respectively. The variations of the presented incremental quantities are given by 


$$
\begin{aligned}
& \delta(\Delta \mathbf{u})=\mathbf{N} \delta(\Delta \mathbf{v}), \\
& \delta\left(\nabla_{0} \Delta \mathbf{u}\right)=\delta(\Delta \mathbf{F})=\mathbf{B}_{\mathrm{F}} \delta(\Delta \mathbf{v}), \\
& \delta\left[\nabla_{0}\left(\nabla_{0} \Delta \mathbf{u}\right)\right]=\delta(\Delta \mathbf{G})=\mathbf{B}_{\mathrm{G}} \delta(\Delta \mathbf{v}) .
\end{aligned}
$$

Upon substitution (19) into Eq. (16) the following discretized relation is obtained

$$
\begin{aligned}
& \int_{V_{0}}\left[\left(\mathbf{B}_{\mathrm{F}} \delta(\Delta \mathbf{v})\right)^{T} \mathbf{P}^{i-1}+\left(\mathbf{B}_{\mathrm{G}} \delta(\Delta \mathbf{v})\right)^{T} \mathbf{Q}^{i-1}\right] \mathrm{d} V_{0}+\int_{V_{0}}\left[\left(\mathbf{B}_{\mathrm{F}} \delta(\Delta \mathbf{v})\right)^{T} \Delta \mathbf{P}+\left(\mathbf{B}_{\mathrm{G}} \delta(\Delta \mathbf{v})\right)^{T} \Delta \mathbf{Q}\right] \mathrm{d} V_{0} \\
& =\int_{A_{0}}(\mathbf{N} \delta(\Delta \mathbf{v}))^{T} \mathbf{t} \mathrm{d} A_{0}+\int_{A_{0}}\left(\mathbf{B}_{\mathrm{F}} \delta(\Delta \mathbf{v})\right)^{T} \mathbf{T} \mathrm{d} A_{0},
\end{aligned}
$$

which can be rewritten in the simplified form as

$$
\int_{V_{0}}\left(\mathbf{B}_{\mathrm{F}}^{T} \Delta \mathbf{P}+\mathbf{B}_{\mathrm{G}}^{T} \Delta \mathbf{Q}\right) \mathrm{d} V_{0}=\int_{A_{0}} \mathbf{N}^{T} \mathbf{t} \mathrm{d} A_{0}+\int_{A_{0}} \mathbf{B}_{\mathrm{F}}^{T} \mathbf{T} \mathrm{d} A_{0}-\int_{V_{0}}\left(\mathbf{B}_{\mathrm{F}}^{T} \mathbf{P}^{i-1}+\mathbf{B}_{\mathrm{G}}^{T} \mathbf{Q}^{i-1}\right) \mathrm{d} V_{0}
$$

The incremental quantities of $\Delta \mathbf{P}$ and $\Delta \mathbf{Q}$ have already been expressed by the constitutive relations (10), which can be transformed by means of Eq. (18) into the form

$$
\begin{aligned}
& \Delta \mathbf{P}={ }^{4} \mathbf{C}_{\mathrm{PF}} \mathbf{B}_{\mathrm{F}} \Delta \mathbf{v}+{ }^{5} \mathbf{C}_{\mathrm{PG}} \mathbf{B}_{\mathrm{G}} \Delta \mathbf{v}, \\
& \Delta \mathbf{Q}={ }^{5} \mathbf{C}_{\mathrm{QF}} \mathbf{B}_{\mathrm{F}} \Delta \mathbf{v}+{ }^{6} \mathbf{C}_{\mathrm{QG}} \mathbf{B}_{\mathrm{G}} \Delta \mathbf{v} .
\end{aligned}
$$

After insertion of Eq. (22) into Eq. (21), the following final element stiffness equation is obtained

$$
\begin{aligned}
& \int_{V_{0}}\left(\mathbf{B}_{\mathrm{F}}^{T{ }^{4}} \mathbf{C}_{\mathrm{PF}} \mathbf{B}_{\mathrm{F}}+\mathbf{B}_{\mathrm{F}}^{T{ }^{5}} \mathbf{C}_{\mathrm{PQ}} \mathbf{B}_{\mathrm{G}}+\mathbf{B}_{\mathrm{G}}^{T}{ }^{5} \mathbf{C}_{\mathrm{QF}} \mathbf{B}_{\mathrm{F}}+\mathbf{B}_{\mathrm{G}}^{T}{ }^{6} \mathbf{C}_{\mathrm{QG}} \mathbf{B}_{\mathrm{G}}\right) \Delta \mathbf{v} \mathrm{d} V_{0}= \\
& \int_{A_{0}} \mathbf{N}^{T} \mathbf{t} \mathrm{d} A_{0}+\int_{A_{0}} \mathbf{B}_{\mathrm{F}}^{T} \mathbf{T} \mathrm{d} A_{0}-\int_{V_{0}}\left(\mathbf{B}_{\mathrm{F}}^{T} \mathbf{P}^{i-1}+\mathbf{B}_{\mathrm{G}}^{T} \mathbf{Q}^{i-1}\right) \mathrm{d} V_{0},
\end{aligned}
$$

which is usually written in the simple matrix form $\mathbf{K} \Delta \mathbf{v}=\mathbf{F}_{\mathrm{e}}-\mathbf{F}_{\mathrm{i}}$, with $\mathbf{K}$ as the element stiffness matrix consisting of the following parts

$$
\mathbf{K}=\mathbf{K}_{\mathrm{PF}}+\mathbf{K}_{\mathrm{PG}}+\mathbf{K}_{\mathrm{QF}}+\mathbf{K}_{\mathrm{QG}} \cdot
$$

As evident from (23), the particular matrices are defined as 


$$
\begin{aligned}
& \mathbf{K}_{\mathrm{PF}}=\int_{V_{0}} \mathbf{B}_{\mathrm{F}}^{T{ }^{4}} \mathbf{C}_{\mathrm{PF}} \mathbf{B}_{\mathrm{F}} \mathrm{d} V_{0}, \\
& \mathbf{K}_{\mathrm{PG}}=\int_{V_{0}} \mathbf{B}_{\mathrm{F}}^{T 5} \mathbf{C}_{\mathrm{PG}} \mathbf{B}_{\mathrm{G}} \mathrm{d} V_{0}, \\
& \mathbf{K}_{\mathrm{QF}}=\int_{V_{0}} \mathbf{B}_{\mathrm{G}}^{T 5} \mathbf{C}_{\mathrm{QF}} \mathbf{B}_{\mathrm{F}} \mathrm{d} V_{0}, \\
& \mathbf{K}_{\mathrm{QG}}=\int_{V_{0}} \mathbf{B}_{\mathrm{G}}^{T 6} \mathbf{C}_{\mathrm{QG}} \mathbf{B}_{\mathrm{G}} \mathrm{d} V_{0} .
\end{aligned}
$$

The values $\mathbf{F}_{\mathrm{e}}$ and $\mathbf{F}_{\mathrm{i}}$ on the right hand-side of the stiffness equation (23) are the external and internal nodal force vectors defined as

$$
\begin{aligned}
& \mathbf{F}_{\mathrm{e}}=\int_{A_{0}}\left(\mathbf{N}^{T} \mathbf{t}+\mathbf{B}_{\mathrm{F}}^{T} \mathbf{T}\right) \mathrm{d} A_{0}, \\
& \mathbf{F}_{\mathrm{i}}=\int_{V_{0}}\left(\mathbf{B}_{\mathrm{F}}^{T} \mathbf{P}^{i-1}+\mathbf{B}_{\mathrm{G}}^{T} \mathbf{Q}^{i-1}\right) \mathrm{d} V_{0} .
\end{aligned}
$$

Here the plane strain two dimensional triangular finite element is proposed. The finite element has three nodes and 36 degrees of freedom with the displacement field approximated by the full fifth order polynomial. The nodal degrees of freedom are the two displacement components and their first and second-order derivatives with respect to the Cartesian coordinates, as shown in Fig. 4. Derivation of the element shape functions and other finite element matrices displayed above is a standard numerical task. For the computation of the element stiffness matrices and force vectors, the Gauss numerical integration method with reduced integration scheme is used. In comparison with the full integration scheme with 25 points, this integration technique with 13 integration points provides quite satisfactory results and it is more convenient for the multiscale analysis, where a discretized RVE is assigned to each point.

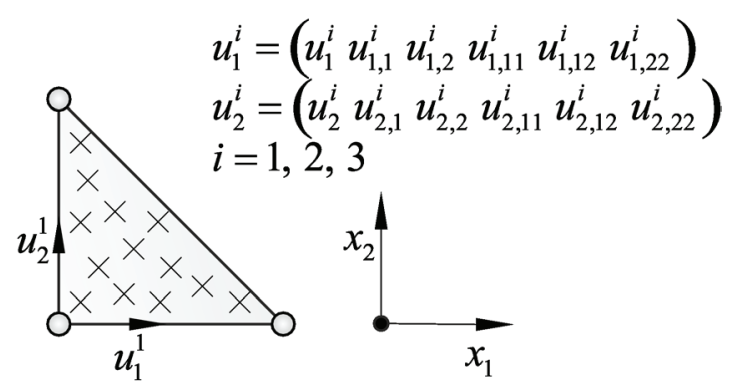

Fig. 4. $C^{1}$ triangular finite element SI. 4. $C$ trokutni konačni element 


\subsection{Finite element implementation and two-scale computation using Abaqus}

The derived finite element formulation together with the described two-scale computational procedure have been implemented into the FE program Abaqus/Standard [32] using user subroutines. The $C^{1}$ finite element shown in the previous section is used at the macrolevel, and it is implemented and coded into Abaqus user element subroutine UEL.

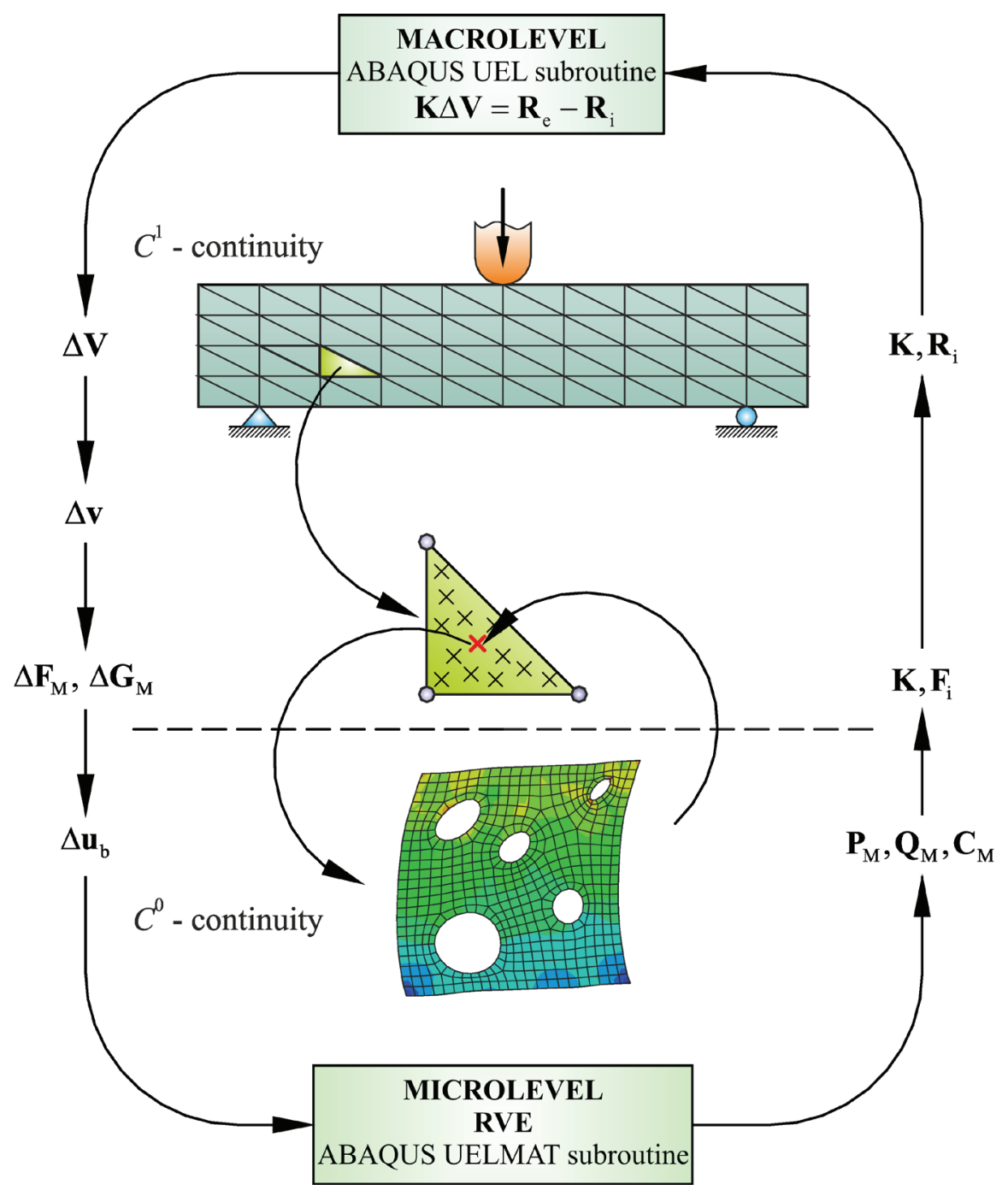

Fig. 5. Scheme of the multiscale algorithm

SI. 5. Shema višeskalnog algoritma 
The element is labeled as C1PE3LS, describing $C^{1}$ continuity and plane strain state assuming large strain formulation. At the microlevel, the RVE is discretized by the plane strain quadrilateral finite element CPE4 taken from the Abaqus element library, where $C^{0}$ continuous interpolations are employed. Such approach takes advantage because the algorithms employing geometrical nonlinearities and different material models available in Abaqus can be applied using the UELMAT subroutine. As well known in nonlinear problems, the incremental-iterative procedure is performed. Accordingly, the load applied at the macrolevel is divided into increments, and in this setting, the microlevel computations are performed as a series of restart analyses. The restart analysis methodology available in the Abaqus relies on the basic assumptions of large strain theory, where a new loading increment is imposed on the last equilibrated configuration, which is applicable to the multiscale framework developed in this paper. In each macroscale computational step the incremental RVE boundary conditions are imposed on the RVE configuration, and after several iterative steps and the satisfying convergence criterion, the RVE output data are mapped at macroscale integration points.

The computational algorithm is summarized in the flowchart in Fig. 5.

\subsection{Finite element verification}

In order to verify the accuracy and convergence of the solutions obtained by the developed higher-order triangular finite element, a simple elastic shear layer problem, usually used as benchmark test in the higher-order formulations e.g. in $[4,5,36]$, is analyzed. The schematic presentations of the geometry, boundary conditions and finite element mesh are given in Fig. 6. The strip height is $H=1 \mathrm{~mm}$ in the $x_{2}$ direction, and it has an infinite length in the horizontal $x_{1}$ direction. Since all field quantities are independent of $x_{1}$ direction, the computational model may comprise only the elements row through the height. Two finite element meshes consisting of 2 and 4 elements over the height are considered, maintaining the element side length ratio of 2.5. As shown in Fig. 6., the bottom boundary is fixed, while a horizontal displacement $u_{1}=u_{0}=0.03 \mathrm{~mm}$ is imposed on the top boundary. Accordingly, the boundary conditions of the bottom and top clamped edges are prescribed by the displacement and deformation gradient components in the following form

$$
\begin{array}{ll}
\text { at bottom boundary }\left(x_{2}=0\right): & u_{1}=0, u_{2}=0, u_{1,2}=0, \\
\text { at top boundary }\left(x_{2}=H\right): & u_{1}=u_{0}, u_{2}=0, u_{1,2}=0 .
\end{array}
$$


Besides, the condition $u_{2}=0$ is prescribed on the left and right boundary nodes along the height, which are imposed by the periodicity conditions enforcing independency of $x_{1}$. Through whole strip height second displacement derivatives $u_{1,21}, u_{2,11}$, $u_{2,21}$ and $u_{2,22}$ are suppressed enabling the horizontal movements of the strip layers. For the sake of comparison, the Mindlin's elastic constitutive model together with the material data are taken from [33]. Thus, the first Piola-Kirchhoff stress tensor and the double stress tensor are expressed as

$$
\begin{aligned}
\mathbf{P}= & \lambda \operatorname{tr}(\nabla \mathbf{u})^{2} \mathbf{1}+2 \mu \nabla \mathbf{u}, \\
\mathbf{Q}= & \frac{l^{2} \mu}{2}\left(\mathbf{G}:{ }^{4} \mathbf{1}+{ }^{4} \mathbf{1}: \mathbf{G}\right)+\frac{l^{2} \mu}{4}\left(\mathbf{G}^{\mathrm{LC}}:{ }^{4} \mathbf{1}+2\left(\mathbf{G}:{ }^{4} \mathbf{1}\right)^{\mathrm{LC}}+{ }^{4} \mathbf{1}: \mathbf{G}^{\mathrm{RC}}\right)+ \\
& l^{2} \mu\left(\mathbf{G}^{\mathrm{LC}}:{ }^{4} \mathbf{1}\right)^{\mathrm{LC}}+l^{2} \mu \mathbf{G}+\frac{l^{2} \mu}{2}\left(\mathbf{G}^{\mathrm{LC}}+\left(\mathbf{G}^{\mathrm{LC}}\right)^{\mathrm{RC}}\right)
\end{aligned}
$$

The material data are the shear modulus $\mu=2000 \mathrm{MPa}$, the bulk modulus $\lambda=3666.67$ $\mathrm{MPa}$ and the material length scale $l=0.05 \mathrm{~mm}$. The deformation response of the strip is displayed by the distribution of the shear strain component $u_{1,2}$ over the height in Fig. 7. The convergence of the numerical solutions obtained by the developed triangular finite element, here labeled as C1PE3LS, towards the analytical result are presented and compared with the solutions obtained by the quadrilateral elements QU8F4L1 and QU8F4L4 based on the mixed formulation taken from [33]. More on the QU8F4L1 and QU8F4L4 finite element formulations can be found in [20]. As evident in Fig. 7., the presented shear strain values obtained by the C1PE3LS element converge quickly with mesh refinement. The analytical solution is achieved only by four C1PE3LS elements, while the results obtained by the five elements QU8F4L1 and QU8F4L4 are far from the analytical solution. In [33] it is shown that twenty elements are needed to reach the analytical values. Thus, it is to conclude that the convergence rate of the element C1PE3LS in the presented shear strain computation is much higher than of the tested quadrilateral elements, which is considered as an advantage of the $C^{1}$ large strain finite element formulation proposed in this contribution. The element C1PE3LS also satisfies the patch test as shown in [31]. 


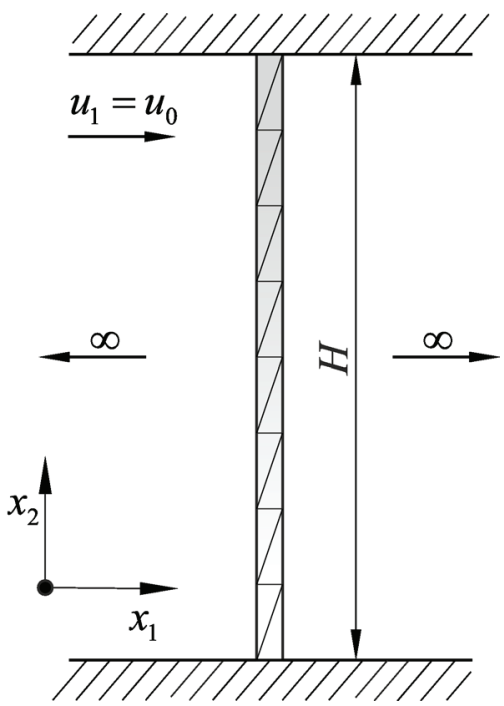

Fig. 6. Discretization of the shear layer strip

Sl. 6. Diskretizacija trake posmičnog sloja

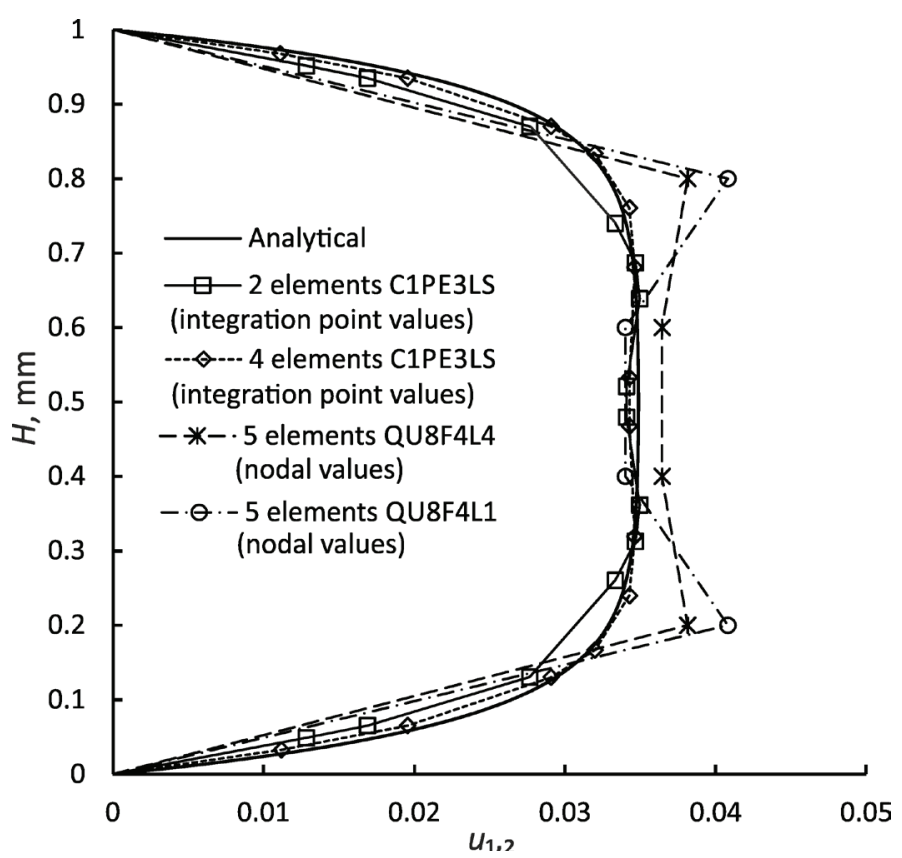

Fig. 7. Distribution of the shear strain along the height of the strip SI. 7. Raspodjela posmičnih deformacija po visini trake 


\section{NUMERICAL EXAMPLES}

In this section, two benchmark numerical examples have been performed to evaluate and test the performance of the second-order micro-macro homogenization approach proposed in this contribution. In the first example, the bending of a rectangular strip under plane strain condition has been analyzed. The results computed by the heterogeneous finite element model are discussed and compared to the solutions obtained for the homogeneous continuum. The second example deals with the modeling of a shear layer problem already studied in $[30,31]$.

\subsection{Rectangular strip under bending}

A rectangular strip of the length and height of $0.2 \mathrm{~m}$ with the thickness of $1 \mathrm{~m}$ subjected to bending is considered. The deformation response of a square model discretized by the 16 plane strain triangular finite elements is studied, as shown in Fig. 8 . a). The imposed loading and boundary conditions yield the deformed configuration of the macro model displaying constant curvature. The material considered is an academic example of an iron with porous microstructure. The material data are the Young's modulus $E=210 \mathrm{GPa}$, the Poisson's ratio $v=0.3$, the yield stress of $250 \mathrm{MPa}$ and the constant elasto-plastic tangent modulus of $250 \mathrm{MPa}$ describing isotropic hardening. This computational problem is analogous to the pure bending example already discussed in [33], where it was shown that the second-order approach is needed to determine the deformation pattern accurately. Here the deformation responses are considered, where the two RVEs with porosities of $13 \%$ and $27 \%$ randomly distributed voids are analyzed, as

a)

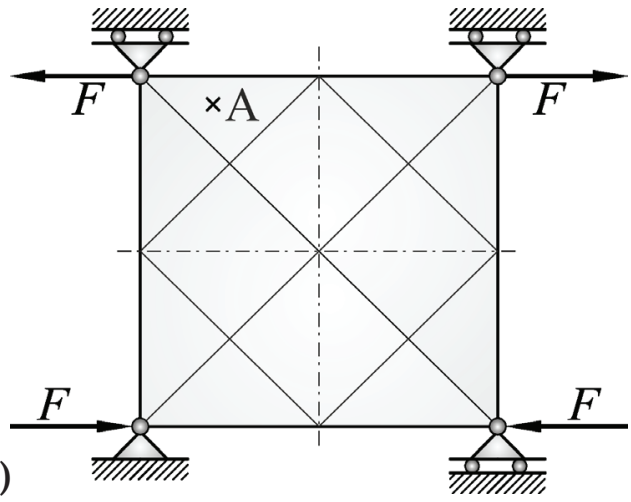

b)

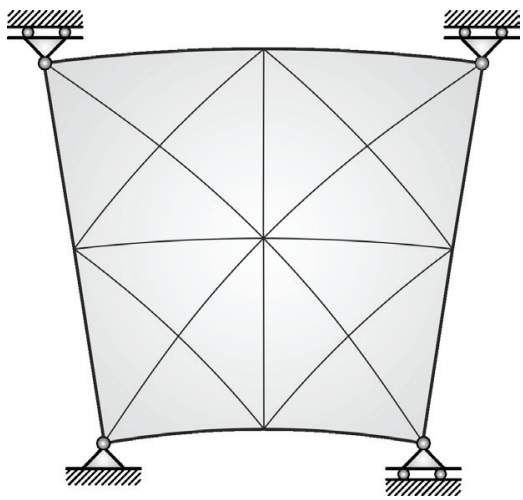

Fig. 8. Bending problem: a) discretization and loading, b) deformed configuration

SI. 8. Problem savijanja: a) diskretizacija i opterećenje, b) deformirani oblik 
a)

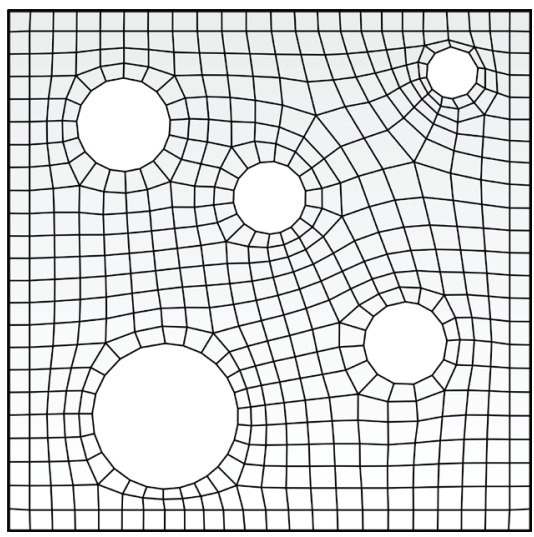

b)

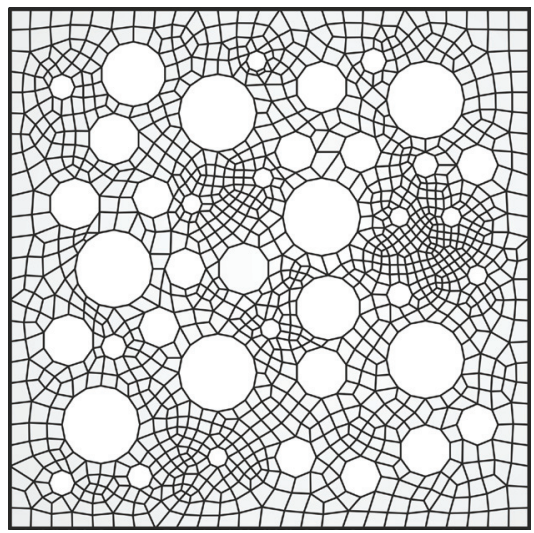

Fig. 9. Representative volume elements with a) $13 \%$ voids, b) $27 \%$ voids

SI. 9. Reprezentativni volumni element s a) $13 \%$ šupljina, b) $27 \%$ šupljina

presented in Fig. 9. The side length of the RVE is taken $0.2 \mathrm{~mm}$. For the sake of comparison, the homogeneous structure is also considered. The RVE discretization has been performed using the quadrilateral finite elements available in the Abaqus. The microlevel discretization with $13 \%$ voids of the average radius of $0.043 \mathrm{~mm}$ is discretized by 508 quadrilateral finite elements, while the discretization of the RVE with $27 \%$ voids

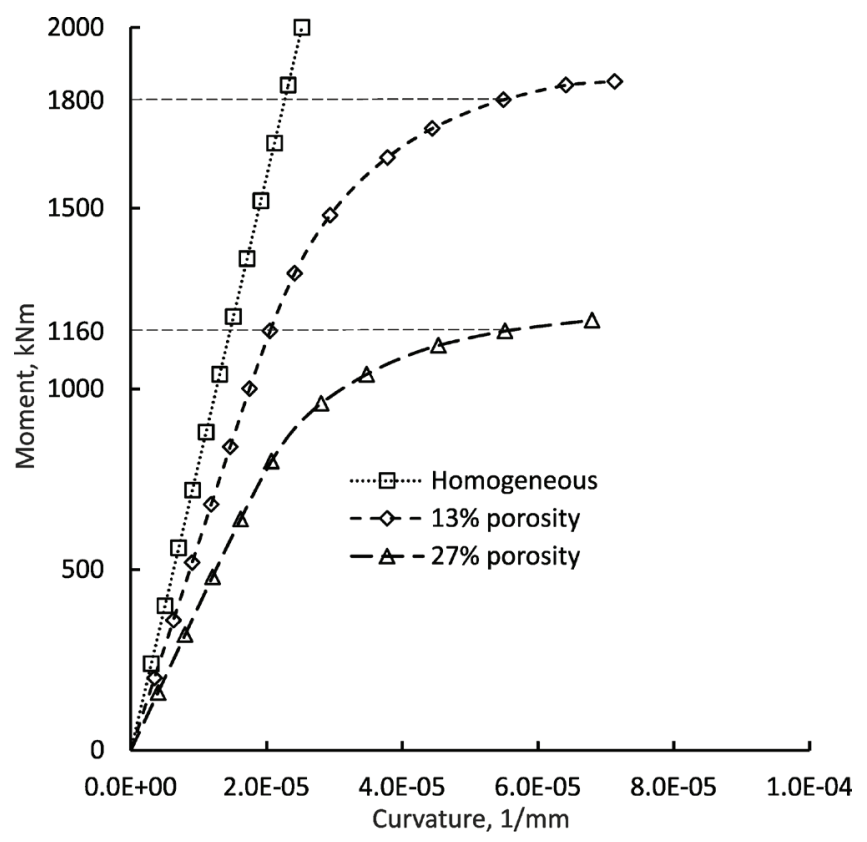

Fig. 10. Moment-curvature diagram

Sl. 10. Dijagram međusobne ovisnosti momenta i zakrivljenosti 
of the average radius of $0.0086 \mathrm{~mm}$ is performed using 1198 quadrilateral elements, as shown in Figs. 9a and 9b.

The moment-curvature diagram presenting the deformation responses for the two different computational variants is shown in Fig. 10. The diagram displays that the stiffness of the analyzed specimens is significantly decreased when the porosity is increased from $13 \%$ to $27 \%$, as expected. Accordingly, for the same curvature the bending moment is significantly reduced if the porosity is increased. It is obvious from Fig. 10. that the structure consisting of the RVE with the porosity of $13 \%$ remains in elastic range at the bending moment of $1160 \mathrm{kNm}$, while a nonlinear response is displayed in the case of $27 \%$ voids.

The distribution of the effective plastic strain over the deformed RVEs at the integration point A, shown in Fig. 8., for the two different bending moments and the porosities displayed in Fig. 9. are presented in Figs. 11. a) and b).

a)

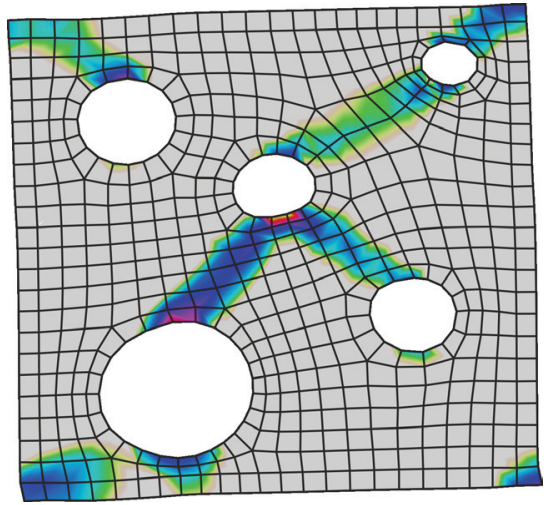

b)

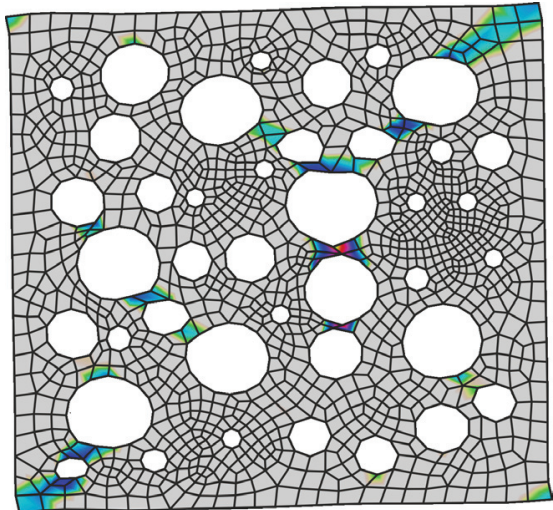

Fig. 11. Distribution of effective plastic strain over RVE at integration point $A$ : a) for bending moment of $1800 \mathrm{kNm}$ and porosity of $13 \%$, b) for bending moment of $1160 \mathrm{kNm}$ and porosity of $27 \%$

SI. 11. Raspodjela efektivne plastične deformacije po reprezentativnom volumnom elementu u integracijskoj točki A: a) za moment savijanja $1800 \mathrm{kNm}$ i poroznosti od 13\%, b) za moment savijanja $1160 \mathrm{kNm}$ i poroznosti od 27\%

\subsection{Elastoplastic shear layer problem}

As the second example, the elastoplastic response of a boundary constrained heterogeneous strip under simple shear is modeled. The elastic shear problem has already been considered in Section 3.3. to verify the accuracy and convergence of the solution obta- 
ined by the finite element developed. The shear layer elastoplastic analysis under small strain assumption has also been performed by the authors of this contribution in [30], and the same example can be found as benchmark problem in numerous contributions dealing with the multiscale analysis of heterogeneous materials $[4,29,34]$. The computational model with clamped boundaries is analogous to that presented in Fig. 6. Here a strip height of $H=10 \mathrm{~mm}$ is considered. According to the experience gathered in the small strain analysis in [30], here 32 elements over the height are used. Same as in [30], the displacement components and their derivatives are suppressed at the top and bottom edges, while the horizontal displacement $u_{0}$ is prescribed at the top edge. The left and right edge are bounded by the periodicity conditions enforcing independency of $x_{1}$.

The material considered is again an academic example of an iron with porous microstructure, which has the same properties as used in the previous numerical example. The square RVE is also unchanged with the side length of $0.2 \mathrm{~mm}$ discretized by 508 quadrilateral finite elements, already presented in Fig. 9. a).

The distribution of the shear strain component $u_{1,2}$ along the height of the strip for the upper edge displacement of $u_{0}=0.1 \mathrm{~mm}$ is presented in Fig. 12. a). The analogous diagram presenting the second-order strain component $u_{1,22}$ is shown in Fig. 12. b). It is to note that $u_{1,2}$ and $u_{1,22}$ are the nodal degrees of freedom of the triangular finite ele-

a)
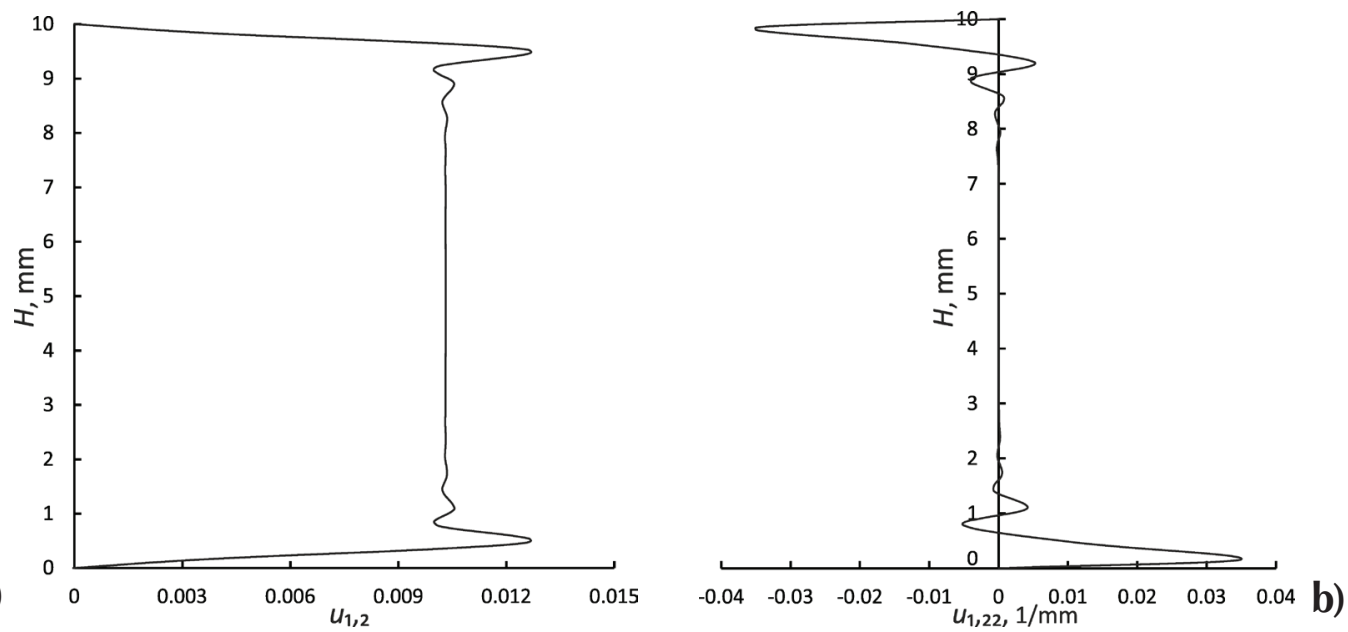

Fig. 12. Distribution along height of the strip: a) shear strain component $u_{1,2}$, b) second-order strain component $u_{1,22}$

SI. 12. Raspodjela duž visine trake: a) komponente posmične deformacije $u_{1,2}$, b) komponente deformacije drugog reda $u_{1,22}$ 
ment applied at the macrolevel. Fig. 13. portrays the distribution of the equivalent plastic strain on a few typical deformed RVEs along the strip. As evident, three characteristic zones can be distinguished. The RVEs positioned at the bottom and top of the strip remain mostly elastic, while the microstructural plastic zones in the form of shear bands are much more developed in the middle of the strip. The shear band is firstly developed in the vertical direction, between the largest voids, and then it spreads across the RVE. It should be stressed that the gradient of the shear microstrains on the boundary layers as well as the pure shear in the middle of the strip have been captured, as expected.

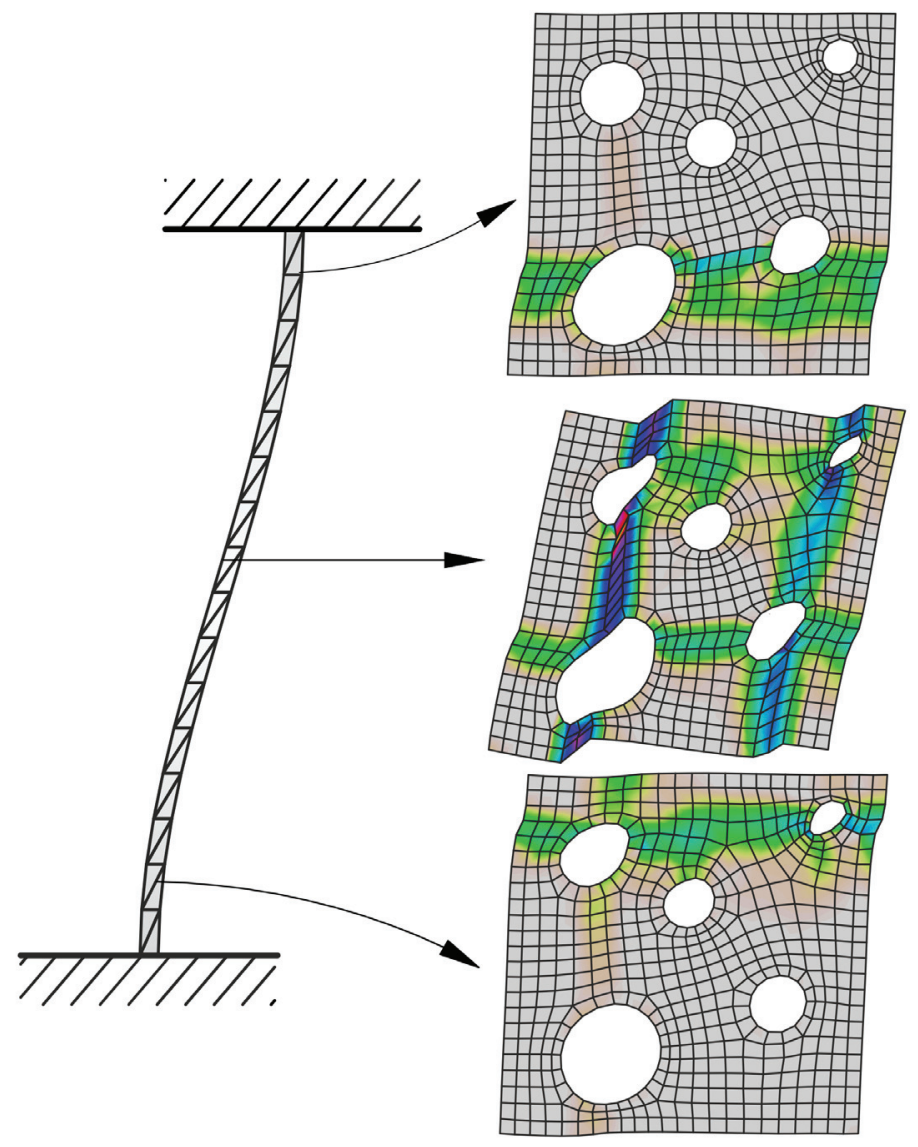

Fig. 13. Distribution of equivalent plastic strain over the selected RVEs along height of the strip for $u_{0}=0.1 \mathrm{~mm}$

SI. 13. Raspodjela ekvivalentne plastične deformacije po odabranim reprezentativnim volumnim elementima duž visine trake za $u_{0}=0.1 \mathrm{~mm}$ 


\section{CONCLUSIONS}

A large strain second-order two-scale formulation for modeling of deformation responses of heterogeneous materials has been presented. A brief overview of the basic relations used at the macrolevel is given, and the homogenization procedure at microscopic level is displayed in more detail. A new $C^{1}$ continuity displacement based finite element formulation employing large strain approach and strain gradient theory is proposed for discretization at macroscopic scale. The accuracy of the finite element formulation is approved by the computation of a simple boundary shear layer problem, usually used as benchmark test. At the shear layer example, the results obtained by the proposed finite element are compared with the analytical solution as well as with the solutions obtained by other finite element formulations. It is shown that the convergence of the proposed triangular finite element in the shear strain computation is much better than of the available quadrilateral elements based on the mixed formulation.

The numerical efficiency of the highly time demanding computational procedure is significantly improved by derivation of the computational strategy based on the Abaqus subroutines. Another advantage of such approach is the possibility of using different computational algorithms as well as material models available in the Abaqus.

To evaluate and test the performance of the second-order micro-macro homogenization approach, the large strain elastoplastic analysis of heterogeneous rectangular strip bending and again boundary constrained shear layer problem are performed. The realistic deformation responses of both examples demonstrate the accuracy of the proposed computational approach.

\section{Acknowledgments}

This work has been supported by Croatian Science Foundation under the project "Multiscale Numerical Modeling of Material Deformation Responses from Macro- to Nanolevel" (2516).

\section{References}

[1] P. Čanžar, Z. Tonković, J. Kodvanj, Microstructure influence on fatigue behaviour of nodular cast iron, Materials Science and Engineering: A, 556 (2012) 88-99.

[2] B. Hassani, E. Hinton, A review of homogenization and topology opimization II - analytical and numerical solution of homogenization equations, Computers \& Structures, 69 (1998) 719-738.

[3] I. Doghri, A. Ouaar, Homogenization of two-phase elasto-plastic composite materials and structures: Study of tangent operators, cyclic plasticity and numerical algorithms, International Journal of Solids and Structures, 40 (2003) 1681-1712. 
[4] V. G. Kouznetsova, M. Geers, W. A. M. Brekelmans, Size of a Representative Volume Element in a Second-Order Computational Homogenization Framework, International Journal for Multiscale Computational Engineering, 2 (2004) 24.

[5] L. K. Kaczmarczyk, C. J. Pearce, N. Bicanic, Scale transition and enforcement of RVE boundary conditions in second-order computational homogenization, International Journal for Numerical Methods in Engineering, 74 (2008) 506-522.

[6] M. H. F. Aliabadi, G. Ugo, Multiscale Modeling in Solid Mechanics, Imperial College Press, London, 2010.

[7] Ä. Temizer, P. Wriggers, An adaptive multiscale resolution strategy for the finite deformation analysis of microheterogeneous structures, Computer Methods in Applied Mechanics and Engineering, 200 (2011) 2639-2661.

[8] T. Wu, İ. Temizer, P. Wriggers, Computational thermal homogenization of concrete, Cement and Concrete Composites, 35 (2013) 59-70.

[9] R. Niekamp, D. Markovic, A. Ibrahimbegovic, H. G. Matthies, R. L. Taylor, Multi-scale modelling of heterogeneous structures with inelastic constitutive behavior, Engineering Computations, 26 (2009) 6-28.

[10] F. Gruttmann, W. Wagner, A coupled two-scale shell model with applications to layered structures, International Journal for Numerical Methods in Engineering, 94 (2013) 12331254.

[11] R. D. Mindlin, Second gradient of strain and surface-tension in linear elasticity, International Journal of Solids and Structures, 1 (1965) 417-438.

[12] R. A. Toupin, Elastic materials with couple-stresses, Archive for Rational Mechanics and Analysis, 11 (1962) 385-414.

[13] S. Akarapu, H. Zbib, Numerical analysis of plane cracks in strain-gradient elastic materials, Int J Fract, 141 (2006) 403-430.

[14] A. Zervos, P. Papanastasiou, I. Vardoulakis, A finite element displacement formulation for gradient elastoplasticity, International Journal for Numerical Methods in Engineering, 50 (2001) 1369-1388.

[15] S. A. Papanicolopulos, A. Zervos, A method for creating a class of triangular C1 finite elements, International Journal for Numerical Methods in Engineering, 89 (2012) 1437-1450.

[16] Z. C. Xia, J. W. Hutchinson, Crack tip fields in strain gradient plasticity, Journal of the Mechanics and Physics of Solids, 44 (1996) 1621-1648.

[17] J. Y. Shu, N. A. Fleck, The prediction of a size effect in microindentation, International Journal of Solids and Structures, 35 (1998) 1363-1383.

[18] E. Amanatidou, N. Aravas, Mixed finite element formulations of strain-gradient elasticity problems, Computer Methods in Applied Mechanics and Engineering, 191 (2002) 1723-1751.

[19] J. Y. Shu, W. E. King, N. A. Fleck, Finite elements for materials with strain gradient effects, International Journal for Numerical Methods in Engineering, 44 (1999) 373-391.

[20] T. Matsushima, R. Chambon, D. Caillerie, Large strain finite element analysis of a local second gradient model: application to localization, International Journal for Numerical Methods in Engineering, 54 (2002) 499-521. 
[21] A. Zervos, S. Papanicolopulos, I. Vardoulakis, Two Finite-Element Discretizations for Gradient Elasticity, Journal of Engineering Mechanics, 135 (2009) 203-213.

[22] H. Askes, E. C. Aifantis, Gradient elasticity in statics and dynamics: An overview of formulations, length scale identification procedures, finite element implementations and new results, International Journal of Solids and Structures, 48 (2011) 1962-1990.

[23] Z. Tang, S. Shen, S. N. Atluri, Analysis of materials with strain-gradient effects: A meshless local Petrov-Galerkin (MLPG) approach, with nodal displacements only, CMES - Computer Modeling in Engineering and Sciences, 4 (2003) 177-196.

[24] S. Skatulla, A. Arockiarajan, C. Sansour, A nonlinear generalized continuum approach for electro-elasticity including scale effects, Journal of the Mechanics and Physics of Solids, 57 (2009) 137-160.

[25] D. Polyzos, K. G. Tsepoura, S. V. Tsinopoulos, D. E. Beskos, A boundary element method for solving 2-D and 3-D static gradient elastic problems: Part I: Integral formulation, Computer Methods in Applied Mechanics and Engineering, 192 (2003) 2845-2873.

[26] G. F. Karlis, S. V. Tsinopoulos, D. Polyzos, D. E. Beskos, Boundary element analysis of mode I and mixed mode (I and II) crack problems of 2-D gradient elasticity, Computer Methods in Applied Mechanics and Engineering, 196 (2007) 5092-5103.

[27] V. Kouznetsova, M. G. D. Geers, W. A. M. Brekelmans, Multi-scale constitutive modelling of heterogeneous materials with a gradient-enhanced computational homogenization scheme, International Journal for Numerical Methods in Engineering, 54 (2002) 1235-1260.

[28] D. J. Luscher, D. L. McDowell, C. A. Bronkhorst, A second gradient theoretical framework for hierarchical multiscale modeling of materials, International Journal of Plasticity, 26 (2010) 1248-1275.

[29] V. G. Kouznetsova, M. G. D. Geers, W. A. M. Brekelmans, Multi-scale second-order computational homogenization of multi-phase materials: a nested finite element solution strategy, Computer Methods in Applied Mechanics and Engineering, 193 (2004) 5525-5550.

[30] T. Lesičar, Z. Tonković, J. Sorić, A second-order two-scale homogenization procedure using C1 macrolevel discretization, Comput Mech, 54 (2014) 425-441.

[31] T. Lesičar, J. Sorić, Z. Tonković, Large strain, two-scale computational approach using continuity finite element employing a second gradient theory, Computer Methods in Applied Mechanics and Engineering, 298 (2016) 303-324.

[32] ABAQUS, ABAQUS/Standard, in: ABAQUS, Dassault Systemes, Providence, RI, USA, 2014.

[33] V. G. Kouznetsova, Computational homogenization for the multi-scale analysis of multiphase materials. Ph. D., TU Eindhoven, Eindhoven, 2002.

[34] V. D. Nguyen, G. Becker, L. Noels, Multiscale computational homogenization methods with a gradient enhanced scheme based on the discontinuous Galerkin formulation, Computer Methods in Applied Mechanics and Engineering, 260 (2013) 63-77.

[35] C. Miehe, A. Koch, Computational micro-to-macro transitions of discretized microstructures undergoing small strains, Arch Appl Mech, 72 (2002) 300-317.

[36] D. J. Luscher, A hierarchical framework for the multiscale modeling of microstructure evolution in heterogeneous materials. Ph.D., Georgia Institute of Technology, Springfield, 2010. 


\title{
VIŠESKALNO NUMERIČKO MODELIRANJE DEFORMIRANJA HETEROGENIH MATERIJALA
}

\begin{abstract}
Sažetak
Prikazan je višeskalni računalni algoritam koji uključuje računalnu homogenizaciju drugoga reda uz pretpostavku velikih deformacija. Izveden je postupak makro-mikro prijenosa varijabli, pri čemu je diskretizacija na makrorazini provedena pomoću razvijenih elemenata temeljenih na pomacima uz zadovoljavanje $C^{1}$ kontinuiteta. Reprezentativni volumni element na mikrorazini diskretiziran je primjenom standardnih elementa koji ispunjavaju $C^{0}$ kontinuitet. Provedena verifikacija predložene $C^{1}$ formulacije pokazuje prednost u usporedbi s postojećim konačnim elementima temeljenim na mješovitoj formulaciji. U svrhu poboljšanja numeričke učinkovitosti računalnih postupaka, novi algoritmi ugrađeni su u program konačnih elemenata Abaqus. Svojstva prikazanog višeskalnog homogenizacijskog postupka pokazana su u numeričkim primjerima u kojima su razmatrani elastoplastični procesi deformiranja.
\end{abstract}

Ključne riječi: Velike deformacije; homogenizacija drugog reda; višeskalni računalni postupak; konačni element s $C^{1}$ kontinuitetom; heterogeni materijali.

\section{Jurica Sorić, Zdenko Tonković, Tomislav Lesičar}

University of Zagreb

Faculty of Mechanical Engineering and Naval Architecture

Ivana Lučića 5, 10000 Zagreb,

E-mail: jurica.soric@fsb.hr; zdenko.tonkovic@fsb.hr; tomislav.lesicar@fsb.hr 